\title{
Characterization of Vibrio cholerae 0139 of an Aquatic Isolate in Northern Vietnam
}

\author{
Dong Tu Nguyen ${ }^{1,2}$, Tuan Cuong Ngo ${ }^{1}$, Huy Hoang Tran ${ }^{1}$, Thanh Huong Le ${ }^{1}$, Hoai Thu Nguyen ${ }^{1}$, \\ Binh Minh Nguyen ${ }^{1}$, Nhu Duong Tran ${ }^{3}$, Tetsu Yamashiro ${ }^{4}$ and Masahiko Ehara ${ }^{5, *}$ \\ ${ }^{1}$ Department of Bacteriology, National Institute of Hygiene and Epidemiology, No.1 Yersin Street, Hanoi, 10, 000, Vietnam \\ ${ }^{2}$ Department of Virology, Institute of Tropical Medicine, Nagasaki University, 1-12-4 Sakamoto, Nagasaki 852-8523, Japan \\ ${ }^{3}$ Department of Epidemiology, National Institute of Hygiene and Epidemiology, No.1 Yersin Street, Hanoi 10, 000, Vietnam \\ ${ }^{4}$ Vietnam Research Station, Institute of Tropical Medicine, Nagasaki University, 1-12-4 Sakamoto, Nagasaki 852-8523, Japan \\ ${ }^{5}$ Department of Bacteriology, Institute of Tropical Medicine, Nagasaki University, 1-12-4 Sakamoto, Nagasaki \\ 852-8523, Japan
}

\begin{abstract}
During the cholera survey in Namdinh province (northern Vietnam) in July, 2010, one strain of Vibrio cholerae O139 was isolated from 7 environmental water samples positive for $\operatorname{ctxA}$, toxR, VCO139 genes and named as V. cholerae O139, ND1 strain. This strain was lysogenic harbouring a genome similar to the filamentous phage fs1. The replicative form DNA of this phage (named as ND1-fs1, $6856 \mathrm{bp}$ ) was sequenced and compared with the other filamentous phages. The filamentous phage ND1-fs1 integrates into the region between $\operatorname{ctx} B$ and $r t x A$ genes. The genetic organization of the CTX $\phi$ of V. cholerae O139, strain ND1 was determined and the schematic representation of the genetic organization was shown together with the ND1-fs1 prophage.
\end{abstract}

Keywords: Vibrio cholerae O139, filamentous phage fs1, ctx gene cassette.

\section{INTRODUCTION}

Vibrio cholerae $\mathrm{O} 139$ Bengal has caused large explosive outbreaks in India, Bangladesh and neighbouring countries since it first appeared in late 1992. In 1993, nine cases were reported from Bangkok, Thailand [1]. In spite of rapid spread of O139 in Southeast Asia, however, little information on cholera in Vietnam due to O139 is available in the national and international scientific literature.

Therefore, we conducted a survey on cholera due to $V$. cholerae 0139 between 2006 and 2010 in Vietnam to shed light on the present situation of $V$. cholerae $\mathrm{O} 139$ in the aquatic environment in Vietnam. During the survey in Namdinh in 2010, we isolated one strain of $V$. cholerae O139 from an aquatic environment. Strains of $V$. cholerae O139 are subtyped according to the organization of CTX $\phi$ [2].

The $6.9 \mathrm{~kb}$ CTX $\phi$ genome contains genes of core and RS2 regions.The core region encodes $\operatorname{ctx} A, B$ and contains genes involved in phage morphogenesis. The RS2 region contains genes required for replication (rstA), integration (rstB) and regulation (rstR) of CTX $\phi$ [3]. The CTX $\phi$ is often flanked by the satellite phage RS1 that contains the

*Address correspondence to this author at the Department of Bacteriology, Institute of Tropical Medicine, Nagasaki University, 1-12-4 Sakamoto, Nagasaki 852-8523, Japan; Tel: +81 95819 7832; Fax: +81 95819 7805;

E-mail: ehara@nagasaki-u.ac.jp $r s t C$ gene in addition to genes present in the RS2 element [4]. Based on the variations in the repressor gene $r s t R$, CTX $\phi$ has been classified into three major types, CTX ${ }^{\text {Class }} \phi$ (Classical type), $\mathrm{CTX}^{\mathrm{ET}} \phi$ (El Tor type), and $\mathrm{CTX}^{\mathrm{Calc}} \phi$ (Calcutta type) [5]. In addition to the CTX $\phi$, another two types of filamentous phage group are reported in $V$. cholerae O139,i.e. fs1 group (fs1, VGJ $\phi$, VSK, VEJ $\phi$ ) and fs2 group (fs2, phage 493).

We report the characterization of $V$. cholerae $\mathrm{O} 139$, strain ND1, first isolated in Vietnam with special attention to the CTX $\phi$ organization and the other filamentous phage integration.

\section{MATERIALS AND METHODS}

\section{Sampling Sites}

Water samples were collected in May 2010 at 14 sites in Namdinh province, including a deep well, a container for rain, and $1 \mathrm{~kg}$ of home made ice. The other 11 samples were collected from a large canal. The ice was left in a sterile plastic beaker to thaw, then transferred into a 1L-bottle. Each water sample was collected $500 \mathrm{ml}$ in a sterile $1 \mathrm{~L}$ glass bottle.

The sampling sites were located $120 \mathrm{~km}$ from the National Institute of Hygiene and Epidemiology (NIHE). The samples were sent to NIHE at room temperature by car as soon as collected. 


\section{Bacteriology}

Each 450-ml water sample was mixed in a $1 \mathrm{~L}$ flask with $50 \mathrm{ml}$ of $10 \mathrm{X}$ alkaline peptone water (Bactopeptone $10 \%$, $\mathrm{NaCl} 10 \%$; pH 8.5) used as an enrichment medium and incubated at $37^{\circ} \mathrm{C}$ for $18 \mathrm{~h}$. Thiosulfate-citrate bile saltssucrose agar (TCBS; Eiken, Tokyo, Japan) was used as the selective medium for the isolation of $V$. cholerae. Presumptive identification was performed on the basis of standard biochemical reactions, including oxidase activity, Gram stain, growth in nutrient broth containing $0 \% \mathrm{NaCl}$, and acid production from glucose, inositol, mannitol, and sucrose. All suspected $V$. cholerae isolates were tested by agglutination tests with polyvalent O1 and O139 antisera. Ten $\mathrm{ml}$ of culture in alkaline peptone water was used for the extraction of genomic DNA.

\section{DNA Extraction from Water Samples}

Ten $\mathrm{ml}$ of alkaline peptone water (primary culture) was harvested by centrifugation at $5000 \mathrm{~g}$ for $10 \mathrm{~min}$ at $4^{\circ} \mathrm{C}$. The pellet was resuspended in $600 \mu \mathrm{l}$ of TESS buffer $(30 \mathrm{mM}$ Tris- $\mathrm{HCl}, \mathrm{pH} 7.5,5 \mathrm{mM}$ EDTA, $25 \%$ sucrose), then supplemented with $200 \mu \mathrm{l}$ of lysozyme $(5 \mathrm{mg} / \mathrm{ml}$ in $10 \mathrm{mM}$ Tris $\mathrm{HCl}$ [pH 8.0]., $1 \mathrm{mM}$ EDTA, $10 \mathrm{mM} \mathrm{NaCl}$ ) and kept at $37{ }^{\circ} \mathrm{C}$ for $30 \mathrm{~min}$. One hundred $\mu$ l of proteinase $\mathrm{K}(10 \mathrm{mg} / \mathrm{ml}$ in autoclaved water)) was added to the suspension and further incubated for $30 \mathrm{~min}$ at $37^{\circ} \mathrm{C}$, then $100 \mu \mathrm{l}$ of $10 \%$ sodium dodecyl sulfate was added and mixed well. DNA was extracted by the phenol chloroform method and ethanol precipitation was performed as described by Maniatis et al., [6]. DNA was recovered using a toothpick, then washed with $70 \%$ ethanol once and with $100 \%$ ethanol once, dried by Micro Vac (TOMY, Tokyo, Japan), then suspended with $200 \mu \mathrm{l}$ of sterilized water and stored at $-20^{\circ} \mathrm{C}$ until use.

\section{DNA Extraction from a Pure Culture}

In the case of pure culture, Vibrio cholerae O139 was grown overnight in $10 \mathrm{ml}$ of LB (Luria-Bertani) broth [6]. Total cellular DNA was extracted and purified as described above.

\section{Multiplex PCR}

The primers used in this study are listed in Table $\mathbf{1 .}$ Amplification with the four primer pairs was performed simultaneously in $0.2 \mathrm{ml}$ microcentrifuge tubes. Samples (1 $\mu 1)$ were added to the PCR mixture in a $30 \mu l$ volume of a final mixture of GoTaq Green Master Mix (Promega, Madison, WI, USA) containing $0.25 \mu \mathrm{M}$ of each pair of primers for toxR, $\operatorname{ctxA}, O 1$, and 0139 . The amplification conditions were as follows: $5 \mathrm{~min}$ at $94^{\circ} \mathrm{C}$ for initial denaturation of DNA and 35 cycles, each consisting of 1 min at $94^{\circ} \mathrm{C}, 1 \mathrm{~min}$ at $55^{\circ} \mathrm{C}, 1 \mathrm{~min}$ at $72^{\circ} \mathrm{C}$, with a final one cycle of extension for $7 \mathrm{~min}$ at $72^{\circ} \mathrm{C}$ in an iCycler (Bio-Rad, CA, USA).

\section{Purification of Replicative form DNA (RF DNA)}

The RF DNA was extracted from a $10 \mathrm{ml}$ culture in LB broth by using the QIAprep Spin Miniprep Kit (Qiagen).

\section{Probes and Hybridization}

Aliquots of DNA (4 $\mu \mathrm{g})$ were digested with restriction enzymes AvaI,BglI, PstI, BglII and HindIII (NIPPON
GENE, Tokyo, Japan), separated by electrophoresis in $1 \%$ agarose gels and blotted on to nylon membrane (Hybond$\mathrm{N+}$; Amersham Pharmacia Biotec) by Southern blotting [14]. The gene probe used to detect $c t x A$ was a $0.56 \mathrm{~kb}$ fragment amplified by PCR from $V$. cholerae A104, an El Tor strain isolated in Kenya in 1983; the CTX $\phi$ core probe was $1.5 \mathrm{~kb}$ fragment amplified from the same strain; RS probe was a 0.9 $\mathrm{kb}$ amplified from the same strain; $r s t R^{E T}$ probe was a $320 \mathrm{bp}$ PCR amplified product from the same strain, zot probe was a $0.84 \mathrm{~kb}$ fragment amplified from the same strain by PCR The probes used for hybridization were labeled with the DIG DNA Labeling and Detection Kit (Roche Molecular Biochemicals, Indianapolis, Ind). For Southern hybridization, the membranes were prehybridized at $42^{\circ} \mathrm{C}$ for $30 \mathrm{~min}$ in a solution containing $2 \mathrm{x}$ SSC (1x SSCis $0.15 \mathrm{M} \mathrm{NaCl}$ plus 0.015 sodium citrate). The membranes were then hybridized with the freshly denatured digoxigenin-labeled gene probes at $42^{\circ} \mathrm{C}$ for $15 \mathrm{~h}$. The hybridized membranes were washed twice in 2x SSC-9.1\% SDS for $5 \mathrm{~min}$ at room temperature and twice in $0.1 \mathrm{x}$ SSC-0.1\% SDS for $15 \mathrm{~min}$ at $68^{\circ} \mathrm{C}$. Non radioactive detection was based on digoxigenin-antidigoxigenin enzyme-linked immunosorbent assay, according to the instructions for the DIG DNA Labeling and Detection Kit instructions. For typing of the filamentous phage, heatdenatured RF DNA of filamentous phage fs 1 was used for Southern blotting after labeling with digoxigenin.

\section{Nucleotide and Protein Sequence Analysis}

Each PCR amplicon was gel purified by using QIAEX ${ }^{\circledR}$ (Qiagen). Nucleotide sequencing of all PCR products was carried out with the Taq Dye-terminator Sequencing Kit (Perkin-Elmer) and an ABI PRISM ${ }^{\circledR} 3100$ Avant Genetic Analyzer (Applied Biosystems). The BLAST program was used to search for homologous DNA and protein sequences in databases.

\section{Electron Microscopy (EM)}

The Filamentous phage from a $V$. cholerae 0139 was purified as reported before [15]. For negative staining, one drop of the phage solution was placed on a sheet of PARAFILM"M" (American Can Co., Greenwich, Conn., U.S.A.) and a Formvar-coated copper grid was floated on the drop for $2 \mathrm{~min}$. The excess solution was removed with filter paper. The specimen was washed 3 times with distilled water, then stained with $1 \%$ uranyl acetate for $30 \mathrm{sec}$. The excess stain was removed by blotting with a filter paper. The specimen was examined with a JEOL JEM 1230 transmission electron microscope operated at $100 \mathrm{kV}$.

\section{Nucleotide Sequence Accession Numbers}

The nucleotide sequences of ND1-fs1, attR, attL regions and $\operatorname{ctx} B$ gene of $V$. cholerae O139, strain ND1 were deposited in the GenBank/EMBL/DDBJ database under accession numbers AB572858, AB646687, AB646688, and AB615200.

\section{RESULTS AND DISCUSSION}

\section{Multiplex PCR}

Seven of the 14 samples were positive for $\operatorname{toxR}, \operatorname{ct} x A$, VCO139 (Fig. 1). 
Table 1. List of Primer used in This Study

\begin{tabular}{|c|c|c|c|}
\hline Primers & Sequences $(5$ to 3 ) & Amplicon Size (bp), Genes & Source or Reference \\
\hline $101-\mathrm{F}$ & CCT TCG ATC CCC TAA GCA ATA C & \multirow{2}{*}{$779($ tox $R)$} & \multirow{2}{*}{ [7] } \\
\hline $837-\mathrm{R}$ & AGG GTT AGC AAC GAT GCG TAA G & & \\
\hline CTX2 & CGG GCA GAT TCT AGA CCT CCT G & \multirow{2}{*}{$564(\operatorname{ctxA})$} & \multirow{2}{*}[8]{} \\
\hline CTX3 & CGA TGA TCT TGG AGC ATT CCC AC & & \\
\hline VCO1-F2-1, & GTT TCA CTG AAC AGA TGG G & \multirow{2}{*}{$192($ VCOl-rfb) } & \multirow{2}{*}{ [9] } \\
\hline VCO1-R2-2, & GGT CAT CTG TAA GTA CAA C & & \\
\hline VCO139-F2, & AGC CTC TTT ATT ACG GGT GG & \multirow{2}{*}{$449($ VCO139-rfb) } & \multirow{2}{*}{ [9] } \\
\hline VCO139-R2 & GTC AAA CCC GAT CGT AAA GG & & \\
\hline CORE-F & CTG TCT TTC CAC AGC GCC G & \multirow{2}{*}{$1.5 \mathrm{~kb}$ (core) } & \multirow{2}{*}{ [10] } \\
\hline CORE-R & CTT TAC TCT CGT GTT GCG GC & & \\
\hline RS-F & CCG GTA CCA CTC ACC TTG TAT TCG & \multirow{2}{*}{$900(R S)$} & \multirow{2}{*}{ [11] } \\
\hline RS-R & CGG GTA CCT CGA CAT CAA ATG GCA TG & & \\
\hline Zot-F & AAA CCT TGA ACG CAT AGC & \multirow{2}{*}{$846(z o t)$} & \multirow{2}{*}{ [11] } \\
\hline Zot-R & GCC CAT AGA CCA CGA TAA & & \\
\hline $\mathrm{RstR}^{\mathrm{ET}}-\mathrm{F}$ & GCA CCA TGA TTT AAG ATG CTC & \multirow{2}{*}{$320\left(r s t R^{E T}\right)$} & \multirow{2}{*}{ [12] } \\
\hline $\operatorname{RstTR}^{\mathrm{ET}}-\mathrm{R}$ & GGC AAT TAA GAC TCA GGC AC & & \\
\hline RstR $^{\text {Class }}$-F & TCT CAT CAG CAA AGC CTC CAT C & \multirow{2}{*}{$243\left(\right.$ rstR $\left.R^{\text {Class }}\right)$} & \multirow{2}{*}[12]{} \\
\hline RstTR $^{\text {Class }}-\mathrm{R}$ & GTA GCA AAT GGT ATC GGC GTT GG & & \\
\hline $\mathrm{RstR}^{\mathrm{Calc}}-\mathrm{F}$ & GCT TTA TCT TAT GGA AGT CTT C & \multirow{2}{*}{$160\left(r s t R^{\text {Calcs }}\right)$} & \multirow[t]{2}{*}{ [12] } \\
\hline RstTR $^{\text {Calc }}-\mathrm{R}$ & GGC AAC AAA GCA CAT TAA AGA C & & \\
\hline 3'zot-F & TCA CTG TTG GTG ATG AGC GT & & This study \\
\hline ctxB-F2 & GCC GCA ATT AGT ATG GCA AA & & [13] \\
\hline attP-L-R & CAA GAT AGC GAT AGC GGC TA & & This study \\
\hline attP-R-F & CTT GAA CTT GTC GCC ACA GA & & This study \\
\hline rtxA-Ri & GTT CAA GCG ATG AGT GGT TT & & This study \\
\hline
\end{tabular}

Surprisingly, a positive sample was found in the ice, which was produced locally under poor hygienic conditions, but the water from a deep well, used for making ice, was negative for $V C O 1, V C O 139$, toxR, $\operatorname{ctxA}$. However, six of the environmental water samples were positive for $V C O 139$, toxR, ctxA. This finding suggested that the ice was contaminated with environmental water, but the actual source of contamination remained unknown. The sampling sites were located along the same canal. The first sampling site is located about $10 \mathrm{~km}$ away from the last sampling site. When an environmental water sample is shown to be positive for ctxA, VCO139, the source of contamination is most likely from clinical cases. The clonality of environmental strains of $V$. cholerae $\mathrm{O} 1$ and $\mathrm{O} 139$ with $c t x A$ gene is closely related with clinical strains [16]. Therefore, the finding of multiplex PCR suggested the presence of sporadic cases of cholera due to $V$. cholerae 0139 in Namdinh province.

\section{Isolation of $V$. cholerae 0139}

Out of seven samples found to be positive for VCO139, ctxA, toxR, we isolated $V$. cholerae 0139 strain from only one sample (lane 1 in Fig. 1). This strain was named as $V$. cholerae O139, ND1. We don't know exactly why only one sample culture was positive among 7 specimens positive for VCO139, ctxA, toxR by PCR But we experience great hardships in isolating $V$. cholerae $\mathrm{O} 1$ and $\mathrm{O} 139$ from the environmental water samples which show positive for $\mathrm{VCO} 1$ or VCO139 and ctxA by PCR. We speculate that the vibrio cell concentration may differ between $10^{3}-10^{8} \mathrm{cfu} / \mathrm{ml}$ among the samples positive for $\operatorname{ctxA}$, toxR, and VCO1 or VCO139. 


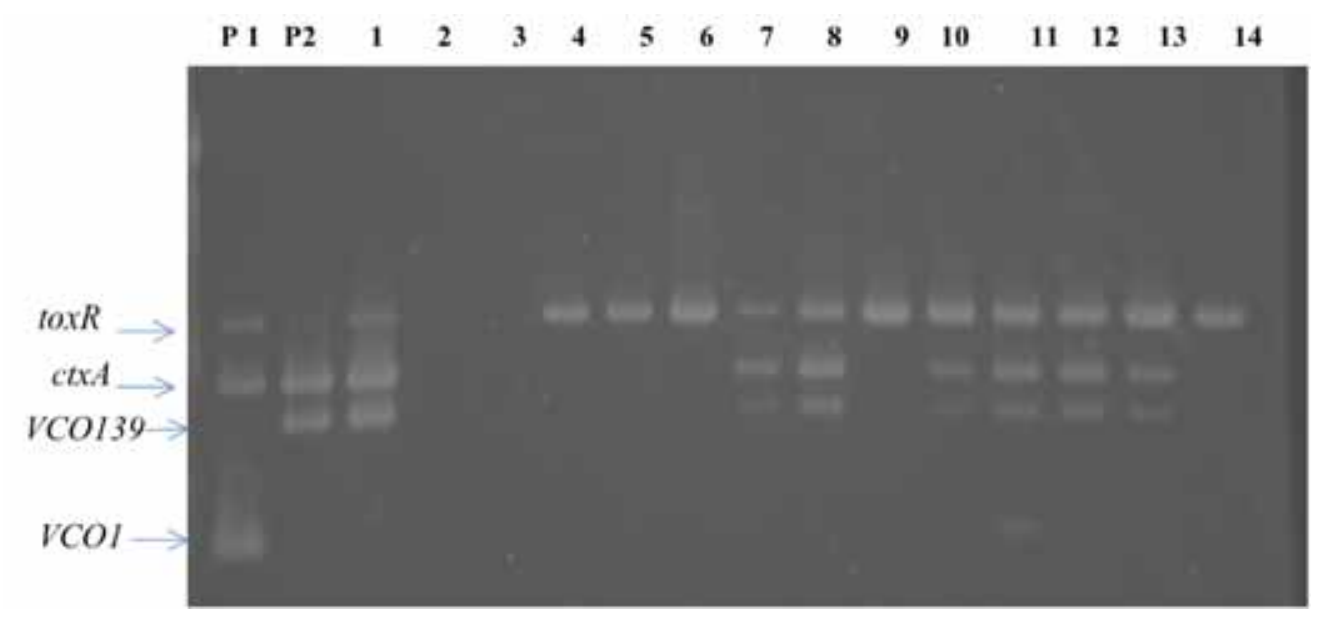

Fig. (1). Multiplex PCR to detect $O 1, O 139, \operatorname{ctxA}$, and toxR genes in environmental water samples in Nam Dinh province in June 2010. Lanes: P1, P2; positive control for VCO1 (strain HN1), VCO139 (strain AI4450) genes, 1; ice locally produced, 2; water from a deep well (150 $\mathrm{m}$ in depth), 3; water from a container for rain with a tight cover, 4-14; water samples from a canal.

This strain was lysogenic and produced filamentous phages similar to fs1 [15] (Figs. 2 and 3). The phage was named ND1-fs1.

\section{Genomic Organization of ND1-fs1}

The ND1-fs1 DNA sequence is similar to sequences of other previously described phages, such as fs1 (96\%) [15], $\operatorname{VGJ} \phi(97 \%)$ [17], VSK (97\%)[18], and $\operatorname{VEJ} \phi(95 \%)$ [19]. The whole genome of ND1-fs1 consisted of 6856 nucleotides and had a $\mathrm{G}+\mathrm{C}$ content of $42.9 \mathrm{~mol} \%$, which is slightly lower than the $\mathrm{G}+\mathrm{C}$ content of its $V$. cholerae host (47.7\% for chromosome I and $46.9 \%$ for chromosome II) [19]. The ND1-fs1 genome has 12 putative ORFs as shown in Fig. (4). It contained RstR, RstA, RstB, RstC, zot like protein, and minor and major coat proteins. This phage was integrated in an environmental $V$. cholerae O139. The role of this type of filamentous phage in pathogenesis remaines to be clarified. The other type of filamentous phage fs2 may play an important role in vivo. These two types

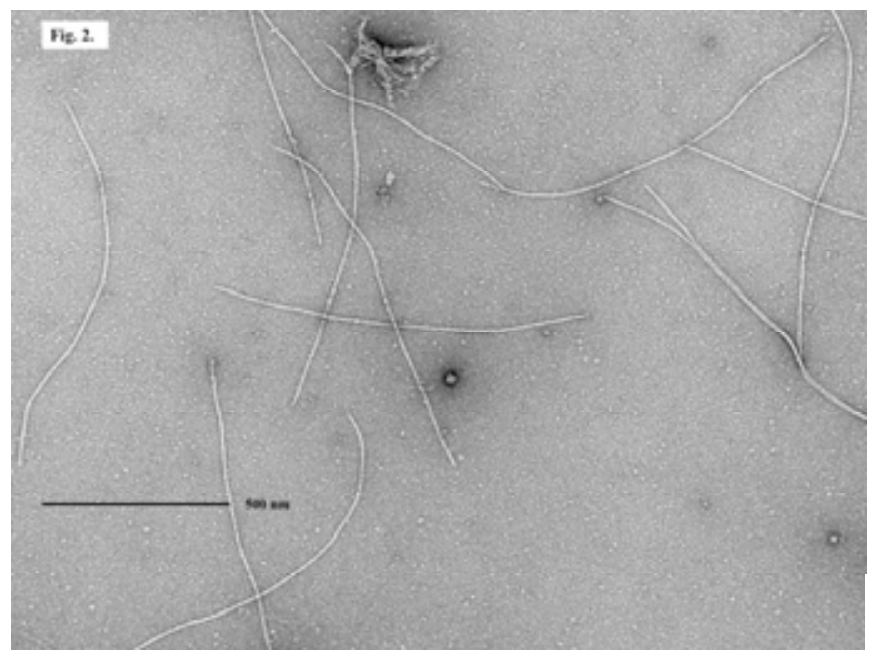

Fig. (2). An EM picture of filamentous phage ND1-fs1 isolated from $V$. cholerae O139, strain ND1. of filamentous phages were found in fresh strains of $V$. cholerae $\mathrm{O} 1$ (manuscript in preparation).

\section{Integration Site for ND1-fs1 in V. cholerae 0139, Strain ND1}

Since the ND1-fs1 phage is similar to fs1, VGJ $\phi$, VSK, and VEJ $\phi$, the integration site for ND1-fs1 was sought between $\operatorname{ctx} B$ and $r t x A$ genes. The two amplicons, ca. $500 \mathrm{bp}$ and $600 \mathrm{bp}$, produced by PCR with the two sets of primers ctxB-F2 / attP-L-R and attP-R-F / rtxA-Ri were exactly the left and right junction, respectively, as revealed by sequencing (Fig. 5). When amplified using the two sets of primers, 3'zot-F/ rtxA-Ri and ctxB-F2 / rtxA-Ri, two amplicons of $2 \mathrm{~kb}$ and $700 \mathrm{bp}$ appeared (Fig. 6). The sequence data of these two amplicons showed that the two sequences were identical to those between $z o t$ and $\operatorname{rtxA}$, and
Gel electrophoresis

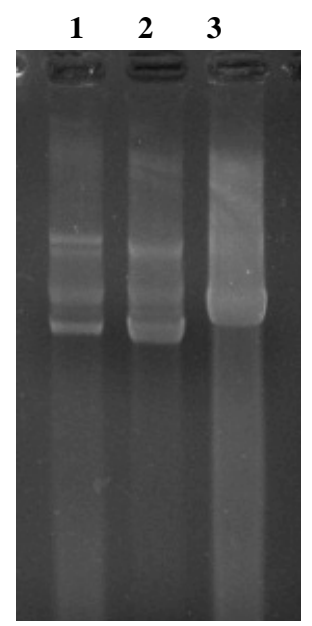

Southern blot

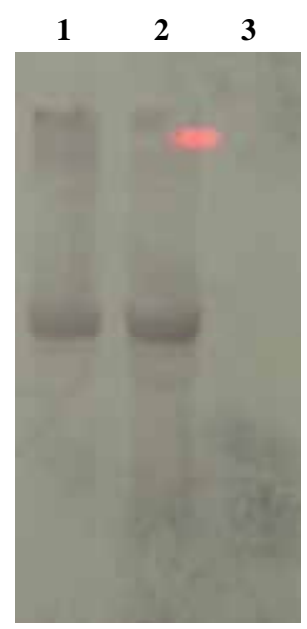

Fig. (3). Southern blot analysis of RF-DNA from $V$. cholerae 0139, strain ND1 probed with RF-DNA of fs1 labeled with digoxigenin. Lane1; RF-DNA extracted from V. cholerae $\mathrm{O} 139$, strain ND1, lames 2, 3; RF-DNA of filamentous phages, fs1 and fs2. 


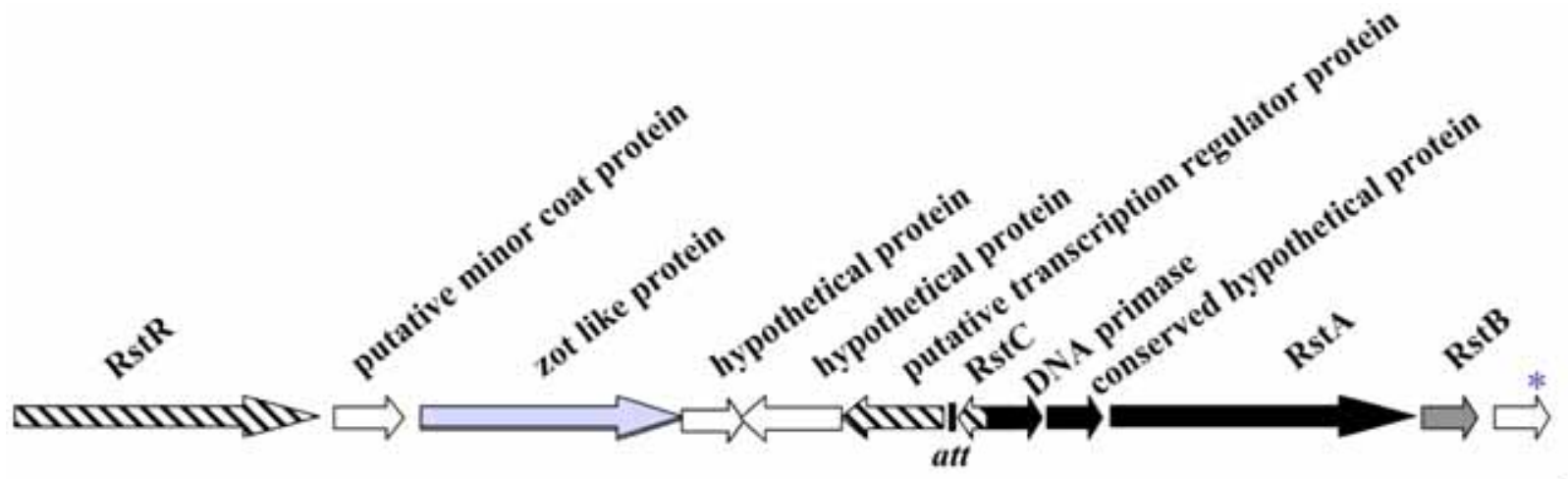

6856 bp

": putative major coat protein precursor

Fig. (4). Modular structure of the genome of ND1-fs1. ORFs are shown with arrows pointing in the direction of transcription. The replication module is represented in black, the structural module in white, and the assembly and secretion module in light grey. The ORFs belonging to the regulation module are hatched. The integration module is represented in dark grey. Genome size is shown on the right. "att" recombination site, similar to $\mathrm{XerCD}$, dif1 recombination site of $V$. cholerae is also shown.

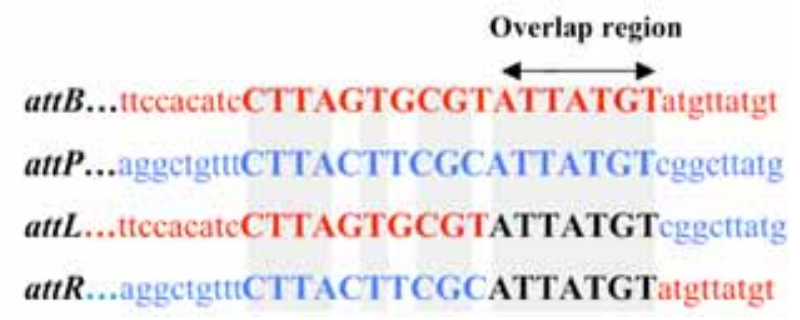

Fig. (5). DNA region with $a t t P, a t t B, a t t L$, and $a t t R$ sites as determined by sequencing. The core homologous sequences are indicated by uppercase letters, and identical nucleotides are indicated by a light grey background. DNA sequences of bacterial origin and DNA sequences of phage origin are indicated by red and blue letters, respectively. Black letters indicate sequences of unknown origin at the moment of recombination. The arrow indicates the putative overlap region, where the cutting and rejoining of the recombination partners took place.
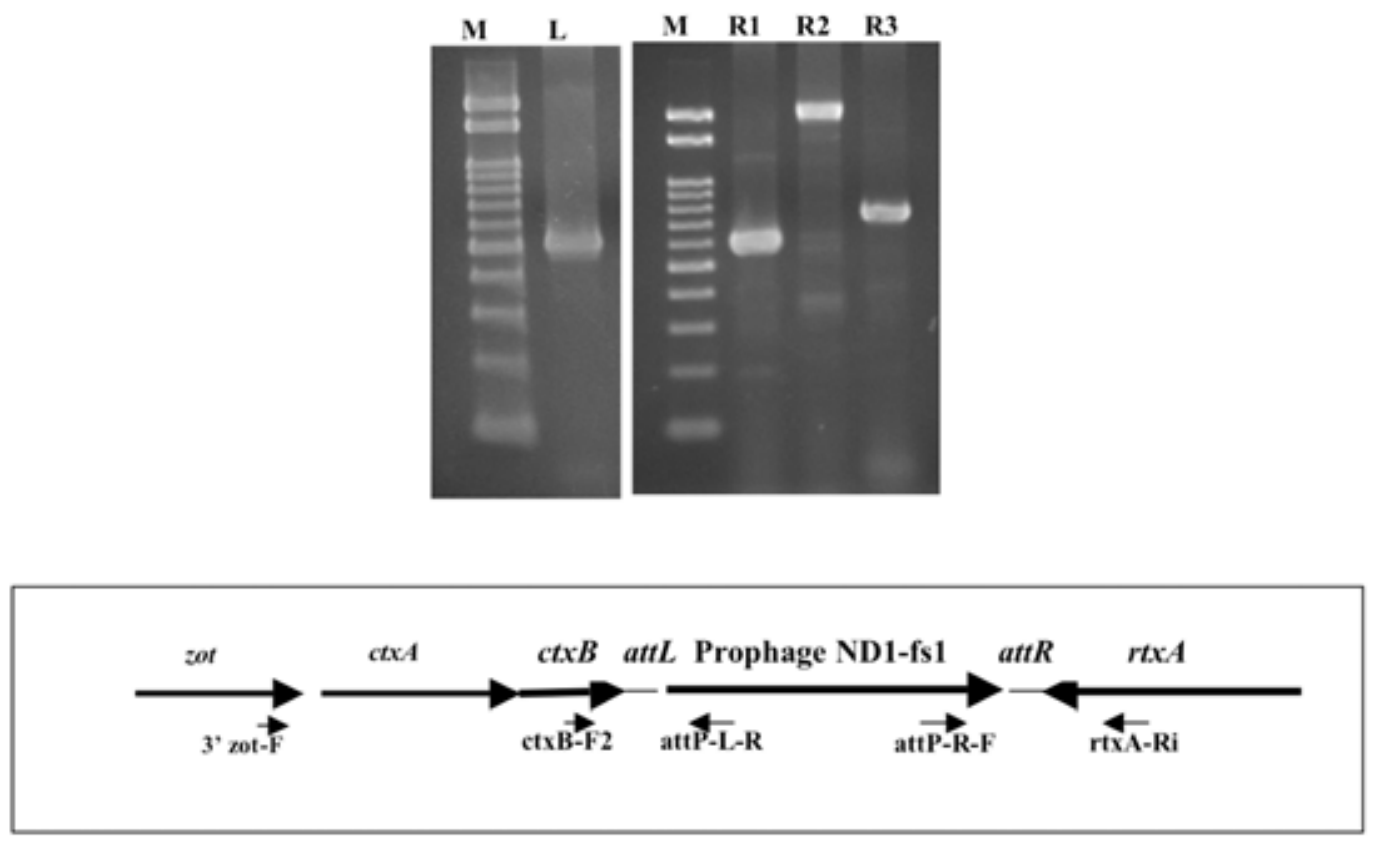

Fig. (6). Determination of the left and right junctions of the ND1-fs1 by PCR. Lane M: marker DNA, 100 bp ladder, lanes L, R1, R2, R3: PCR products obtained using ctxB-F2/ attP-L-R (left junction), attP-R-F/ rtxA-Ri (right junction), 3' zot-F/ rtxA-Ri, and ctxB-F2/ rtxA-Ri primers (ND1-fs1 is not integrated). Each primer site is shown in the lower box. 


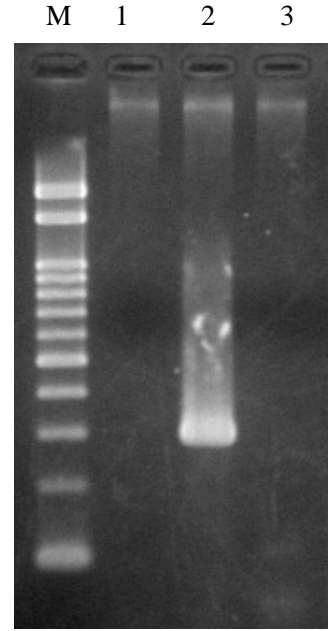

Fig. (7). Detection of rstR $\mathrm{ral}^{\mathrm{Cal}}, \mathrm{rstR}^{\mathrm{ET}}$, and $\mathbf{r s t R}^{\text {Class }}$ by PCR in $V$. cholerae 0139, strain ND1. Lane M: marker DNA, 100 bp DNA ladder, lanes 1, 2, 3: $\mathrm{rstR}^{\mathrm{Cal}}$, $\mathrm{rstR}^{\mathrm{ET}}$, and $\mathrm{rstR}^{\text {Class }}$, respectively.

between $c t x B$ and $r t x A$ genes, respectively, without integration by ND1-fs1, even though DNA extracted from the lysogenic strain was used as a template. A similar result was reported from K139 phage [20], suggesting that the template DNA from any type of lysogenic strain is a mixture of two types of bacteria, lysogenic and non-lysogenic, probably due to spontaneous curring. The DNA regions with $a t t P, a t t B, a t t L$ and $a t t R$ sites are shown in Fig. (5). The attP sequence of ND1-fs1 was similar to that of VGJ $\phi$, but the $a t t B$ sequence of $V$. cholerae $\mathrm{O} 139$, strain ND1 was different from that of strain N16961 [17].

\section{Genetic Organization of CTX $\phi$ of $V$. cholerae 139, Strain ND1}

Diverse CTX phages among Vibrio cholerae O139 were reported [21-26].In rst $R$ allele specific PCR, this strain (ND1) produced an amplicon of $320 \mathrm{bp}$ corresponding to El Tor type of rstR without amplicons of $\mathrm{rstR}^{\mathrm{Calc}}$ and $\mathrm{rstR}^{\text {Class }}$ (Fig. 7). This prompted us to investigate the arrangement of CTX element in this strain. To determine the copy number and the arrangement of CTX genetic element, DNA from strain ND1 was digested with different restriction enzymes with recognition sites within the CTX element. Southern blot hybridization of chromosomal DNA digested with AvaI, BglI, PstI, BglII, and HindIII revealed a single band with ctxA probe (Fig. 8a), a single band with AvaI, BglI, BglII, HindIII, and two bands with PstI on hybridization with core probe (Fig. 8b). The hybridization patterns between RS and rstR $^{\mathrm{ET}}$ probes (Fig. 8c and d) were similar in the $2.7 \mathrm{~kb}$ band. The presence of $2.7 \mathrm{~kb}$ band in this strain suggests the presence of tandemly arranged RS1 element upstream of CTX $\phi$ prophage. The higher intensity of $2.7 \mathrm{~kb}$ fragment revealed with the $\mathrm{RS}$ and $\mathrm{rstR}^{\mathrm{ET}}$ probes (Fig. 8c and d, lane BII) suggested the presence of more than one copy of the $\mathrm{rstR}^{\mathrm{ET}}$ gene. The restriction enzyme BglII has one site in rstR $^{\mathrm{ET}}$ The hybridization pattern with zot probe showed a single band with AvaI, PstI, BglII and two bands with BglI (a) $\operatorname{ctxA}$

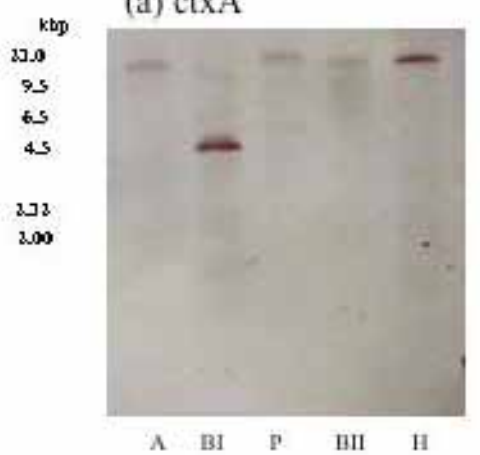

(d) rstR ${ }^{\mathrm{ET}}$

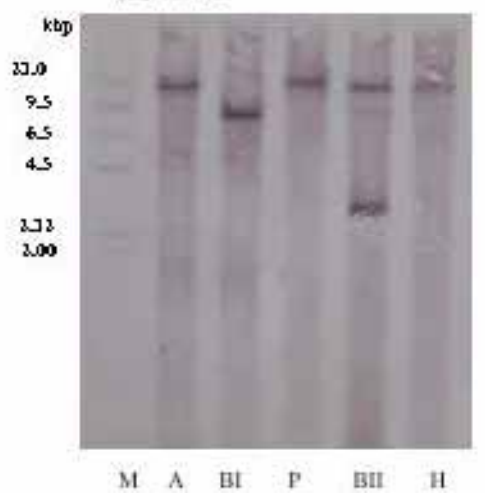

(b) core

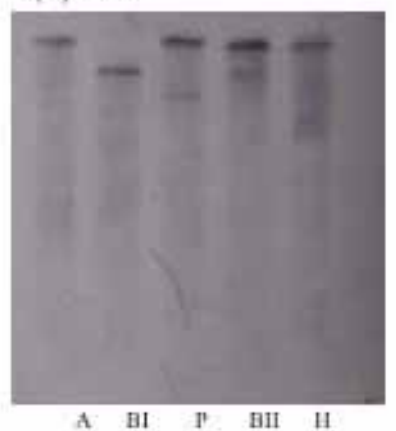

(e) zot

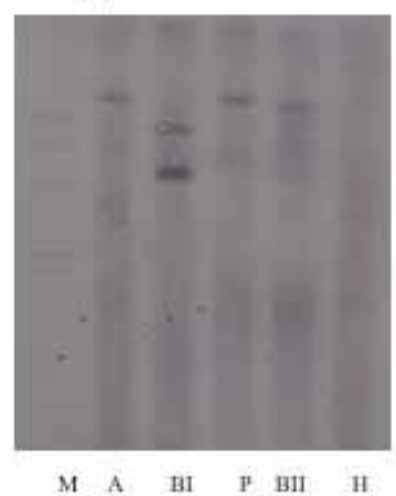

(c) RS

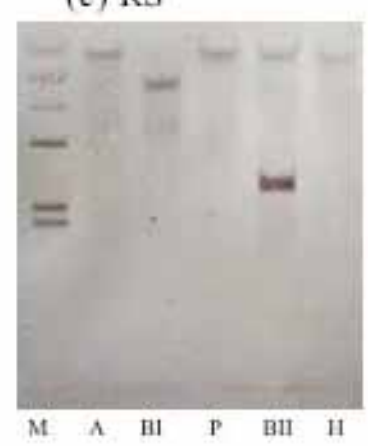



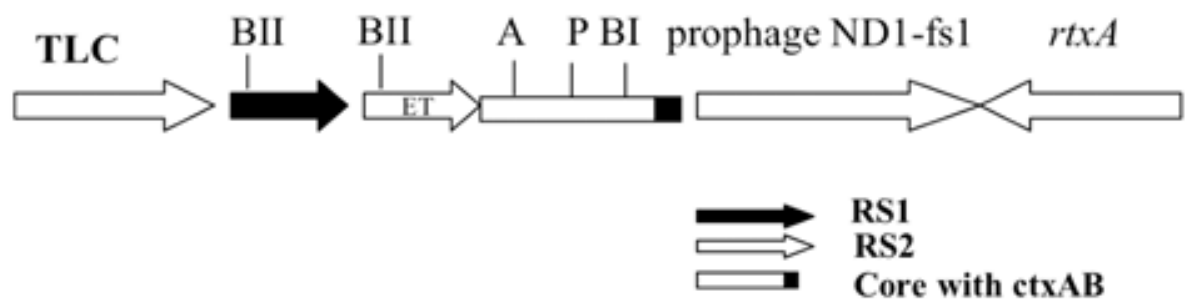

Fig. (9). Schematic representation of genetic organization of CTX $\phi$ of V. cholerae O139, strain ND1.

and HindIII. Based on the hybridization and PCR data, the organization of CTX $\phi$ in $V$. cholerae O139, strain ND1 is presented in Fig. (9).

In conclusion, $V$. cholerae $\mathrm{O} 139$ seemed to spread widely in the environmental water sources in northern Vietnam. Our findings suggested the significance of testing diarrhea specimens with attention to $V$. cholerae $\mathrm{O} 139$. We found an environmental strain of $V$. cholerae $\mathrm{O} 139$ with an integrated filamentous phage. Filamentous phages of $V$. cholerae were reported after the appearance of $V$. cholerae $\mathrm{O} 139$ [15, 27]. We speculate some difference in maintaining the lysogenicity between $V$. cholerae $\mathrm{O} 1$ and $\mathrm{O} 139$. The strain of ND1 has an El Tor type of $\operatorname{ctxB}$ gene (AB15200) and a single copy of the ctx gene. Most strains isolated in India in 1993 had two copies of the ctx gene in tandem connected by two RSs [28]. Previously we reported the integration sites of vibriophage fs2 in a classical strain and in a strain of $V$. cholerae O139 [29]. It is noteworthy to examine whether two filamentous phages, fs1 and fs2 integrate into the chromosome of epidemic strains of $V$. cholerae $\mathrm{O} 1$ at the same time as shown in this study and the previous study [29] flanking the CTX phage.

\section{CONFLICT OF INTEREST}

The authors have no conflicts of interest to report.

\section{ACKNOWLEDGMENT}

We acknowledge the financial support received from the Ministry of Science and Technology, Vietnam. We are grateful to the Japan Society for the Promotion of Science (CORE UNIVERSITY PROGRAM) and Global COE Program of Ministry of Education, Culture, Sports, Science and Technology of Japan for supporting this study. This work was also supported by the Program of Japan Initiative for Global Research Network on Infectious Diseases (JGRID, MEXT, Japan) .

\section{REFERENCES}

[1] Chongsa-nguan M, Chaicumpa W, Moolasart $\mathrm{P}$, et al. Vibrio cholera O139 Bengal in Bangkok. (Letter). Lancet 1993; 342: 430-1.

[2] Mantri CK, Mohapatra SS, Colwell RR, Singk DV. Sequence analysis of Vibrio cholerae orf $U$ and zot from pre-CTX $\phi$ and CTX $\phi$ reveals multiple origin of pre-CTX $\phi$ and CTX $\phi$. Environmental Microbiol Rep 2010; 2: 67-75.

[3] Waldor MK, Rubin EJ, Pearson GD, Kimsey H, Melalanos JJ. Regulation, replication, and integration functions of the Vibrio cholerae CTX $\phi$ are encoded by region RS2. Mol Microbiol 1997; 24: 917-26.

[4] Davis BM, Waldor MK . CTX $\phi$ contains a hybrid genome derived from tandemly integrated elements. Proc Natl Acad Sci USA 2000; 97: 8572-7.
[5] Nusrin S, Khan GY, Bhuiyan NA, et al. Diverse CTX phages among toxigenic Vibrio vholerae $\mathrm{O} 1$ and $\mathrm{O} 139$ strains isolated between 1994 and 2002 in an area where cholera is endemic in Bangladesh. J Clin Microbiol 2004; 42: 5854-6.

[6] Maniatis T, Fritsch EF, Sambrook J. Molecular cloning: a laboratory manual. New York: Cold Spring Harbor 1982.

[7] Rivera ING, Chun J, Huq A, Sack RB, Colwell RR. Genotypes associated with virulence in environmental isolates of Vibrio cholerae. Appl Environ Microbiol 2001; 67: 2421-9.

[8] Fields PI, Popovic T, Wachsmuth K, Olsvik O. Use of Polymerase Chain Reaction for detection of toxigenic Vibrio cholerae O1 strains from the Latin American cholera epidemic. J Clin Microbiol 1992; 30: 2118-21

[9] Hoshino K, Yamasaki S, Mukhopadhyay AK, et al. Development and evaluation of a multiplex PCR assay for rapid detection of toxigenic Vibrio cholerae O1 and O139. FEMS Immunol Med Microbiol 1998; 20: 201-7.

[10] Ledon T, Campos J, Suzarte E, et al. El Tor and Calcutta CTX $\phi$ precursors coexisting with intact CTX $\phi$ copies in Vibrio cholerae O139 isolates. Res Microbiol 2008; 159: 81-7.

[11] Qu M, Xu J, Ding T, et al. Molecular epidemiology of Vibrio cholerae O139 in China: Polymorphism of Ribotypes and CTX elements. J Clin Microbiol 2003; 41: 2306-10.

[12] Mantri CK, Mohapatra SS, Signh DV. Effect of storage and sodium chloride on excision of СТХ $\phi$ or pre-CTX $\phi$ and CTX $\phi$ from Vibrio cholerae O130 strains. Infect Genet Evol 2010; 10: 925-30.

[13] Maiti D, Das B, Saha A, et al. Genetic organization of pre-CTX and CTX prophages in the genome of an environmental Vibrio cholerae non-O1, non-O139 strain. Microbiol 2006; 152: 3633-41.

[14] Southern EM. Detection of specific sequences among DNA fragments separated by gel electrophoresis. J Mol Biol 1975; 98 : 503-17.

[15] Ehara M, Shimodori S, Kojima F, et al. Characterization of filamentous phages of Vibrio cholerae O139 and O1. FEMS Microbiol Lett 1997; 154: 293-301.

[16] Singh DV, Matta MH, Matte GR, et al, Molecular analysis of Vibrio cholerae O1, O139, non-O1, and non-O139 strains: Clonal relationships between clinical and environmental isolates. Appl Environ Microbiol 2001; 67: 910-21.

[17] Campos J, Martinez E, Suzarte E, et al. VGJ $\phi$, an novel filamentous phage of Vibrio cholerae, integrates into the same chromosomal site as CTXф. 2003; 185: 5685-96.

[18] Kar S, Ghosh RK, Ghosh AN, Ghosh A. Integration of the DNA of a novel filamentous phage VSK from Vibrio cholerae O139 into the host chromosomal DNA. FEMS Microbiol Lett 1996; 145: 17-22.

[19] Campos J, Martinez E, Izquierdo Y, Fando R. VEJ filamentous phage of Vibrio cholerae able to transduce the cholera toxin genes. Microbiol 2010; 156: 108-15.

[20] Nesper J, Blaß J, Foutoulakis M, Reidl J. Characterization of the major control region of Vibrio vcholerae bacteriophage K139: Immunity, exclusion, and integration. J Bacteriol 1999; 181: 2902-13.

[21] Nusrin S, Khan GY, Bhuiyan NA, et al. Diverse CTX phage among toxigenic Vibrio cholerae $\mathrm{O} 1$ and $\mathrm{O} 139$ strains isolated between 1994 and 2002 in an area where cholera is endemic in Bangladesh. J Clin Microbiol 2004; 42: 5854-6.

[22] Kimsey HH, Nair GB, Ghosh A, Waldor MK Diverse CTX $\phi$ and evolution of new pathogenic Vibrio cholerae. Lancet 1998; 352: 457-8. 
[23] Davis BM, Kimsey HH, Chang W, Waldor MK. The Vibrio cholerae O139 Calcutta bacteriophage CTX $\phi$ is infected and encodes a novel repressor. J Bacteriol 1999; 181: 6779-87.

[24] Mukhopadhyay AK, Chakaraborty S, Takeda Y, Nair GB, Berg DE. Characterization of VPI pathogenicity island and CTX $\phi$ prophage in environmental strains of Vibrio cholerae, J Bacteriol 2001; 183: 4737-46.

[25] Ledon T, Campos J, Suzarte E, Rodriguez B, Marrero K, Fando R. El Tor and Calcutta CTX $\phi$ precursors coexisting with intact CTX $\phi$ copies in Vibrio cholerae O139 isolates. Res Microbiol 2008; 159: $81-7$.

[26] Bhuiyan NA, Alam M, Motita M, et al. Changing genotypes of cholera toxin (CT) of Vibrio cholerae O139 in Bangladesh and description of three new CT genotypes. FEMS Immunol Med Microbiol 2009; 57: 136-41.

[27] Kar S, Ghosh RK, Ghosh AN, Ghosh A. Integration of the DNA of a novel filamentous bacteriophgae VSK from Vibrio cholerae O139 into the host chromosomal DNA. FEMS Miceobiol Lett 1996; 145: 17-22.

[28] Bhadra RK, Roychoudhury S, Banerjee RK, et al. Cholera toxin (CTX) genetic element in Vibrio cholerae O139. Microbiol 1995; 141: 1977-83.

[29] Nguyen DT, Nguyen BM, Tran HH, et al. Filamentous vibriophage fs2 encoding the $r s t C$ gene integrates into the same chromosomal region as the CTX phage. FEMS Microbiol Lett 2008; 284: 225-30.

(C) Nguyen et al.; Licensee Bentham Open.

This is an open access article licensed under the terms of the Creative Commons Attribution Non-Commercial License (http://creativecommons.org/licenses/ by-nc/3.0/) which permits unrestricted, non-commercial use, distribution and reproduction in any medium, provided the work is properly cited. 